Lefkowitz, J. (1977). Industrial-organizational psychology and the police. American Psychologist, 32(5), 346-364.

Ruggs, E. N., Hebl, M. R., Rabelo, V. C., Weaver, K. B., Kovacs, J., \& Kemp, A. S. (2016). Baltimore is burning: Can I-O psychologists help extinguish the flames? Industrial and Organizational Psychology: Perspectives on Science and Practice, 9(3), 525-547.

Scrivner, E. M. (1994). Controlling police use of excessive force: The role of the police psychologist. Washington, DC: National Institute of Justice.

\title{
Broadening the Lens of Stereotype and Bias: Perspectives From Charm City
}

Sally D. Farley and Rebecca J. Thompson

University of Baltimore

In the focal article, Ruggs et al. (2016) outline the ways in which psychological theory and research can provide insight into the potential underlying processes behind recent conflict between law enforcement officials and the community. These incidents have led to national questions regarding the training and standard operating procedure of police, as well as society's beliefs about the prevalence of stereotyping. The authors identify how psychological research, and social psychological and industrial-organizational research in particular, can play a role in shaping these issues for organizational practices moving forward.

We agree that psychologists can and should play a pivotal role in understanding and shaping these issues. As psychologists who were living and working in Baltimore during one of the incidents cited in the focal article and who care deeply about the Baltimore community that was so profoundly affected by the unrest, we feel compelled to add our voice into the conversation about the unique role that researchers have in addressing social and organizational questions. However, we contend that while psychologists are currently studying these questions, some of the most relevant research may contribute controversial and complex findings, findings that may not suggest a "one-size-fits-all" solution. In line with this, we assert that the best methods for addressing these issues within organizations involve reducing the unique stressors that exacerbate implicit bias rather than developing selection procedures to identify potential bias. The focus of our commentary is to highlight

Sally D. Farley and Rebecca J. Thompson, Division of Applied Behavioral Sciences, University of Baltimore.

The authors contributed equally, and the author order is alphabetical.

Correspondence concerning this article should be addressed to Sally D. Farley, Division of Applied Behavioral Sciences, University of Baltimore, 1420 North Charles Street, Baltimore, MD 21201. E-mail: sfarley@ubalt.edu 
recent research examining these specific issues in order to offer more nuanced solutions that can meaningfully serve organizations, employees, and applicants, all of whom operate within a highly regulated legal context.

\section{Stereotype and Bias}

As Ruggs et al. identify, psychologists have conducted considerable research examining issues surrounding stereotype and bias. Although Ruggs and colleagues highlight classic examples of bias research and appropriately point out the gravity of anti-Black police shooting bias as demonstrated by Ross (2015) and Mekawi and Bresin (2015), recent experimental studies illustrate that the behavioral consequences of bias are not uniform. We contend that focusing on a limited and outdated subset of research essentially presents an overly simplistic picture of the stereotyping literature. Below, we outline some of the important contributions from recent studies examining stereotype and bias.

Devine's (1989) seminal article on the dual process theory of stereotype activation provided the foundation for the distinction between automatic, implicit stereotype activation and a secondary, more thoughtful, controlled effortful process. Devine's work found that one's implicit attitudes are often in conflict with one's conscious explicit attitudes and that counteracting the effects of implicit bias is cognitively taxing. We are in agreement with Ruggs et al. that harmful stereotypes, activated outside of conscious awareness, may have deleterious consequences for interactions between police officers and members of the community. However, recent empirical findings call into question the notion that the default behavioral response to implicit racial bias is negative or aggressive interpersonal behavior toward racial minorities. First, let us critically examine the most commonly used measurement of implicit attitudes, the Implicit Attitudes Test (IAT).

\section{Implicit Attitudes Test (IAT)}

The IAT, created by Greenwald, McGhee, and Schwartz (1998), is regarded by some scholars as a valid measure of implicit attitudes (Greenwald, Poehlman, Uhlmann, \& Banaji, 2009), yet a recent comprehensive metaanalysis has cast great doubt into that conclusion (Oswald, Mitchell, Blanton, Jaccard, \& Tetlock, 2013). Oswald et al. (2013) offered convincing evidence of the poor predictive validity of the IAT, writing that "IATs were poor predictors of every criterion category other than brain activity, and the IATs performed no better than simple explicit measures" (p. 171). In addition, based on the IAT, roughly $90 \%-95 \%$ of individuals in the population possess negative implicit attitudes to some degree (Arkes, \& Tetlock, 2004; Blanton, \& Jaccard, 2006; Rothermund \& Wentura, 2004). Therefore, we contend that an important conclusion from these studies is that employing a selection 
method that intends to "screen out" individuals for racial bias would not be an accurate way to identify biased individuals, as the majority of the population holds these attitudes to varying degrees, and there is doubt about the correspondence between the IAT and behavior.

Indeed, as Ruggs et al. contended, negative implicit attitudes may be associated with biased negative behavioral responses (Vanman, Saltz, Nathan, \& Warren, 2004). However, interacting with individuals from other races prompts a heightened awareness and anxiety over appearing racist (Crandall \& Eshleman, 2003). This motivation can, in some settings, prompt individuals to engage in stereotype overcorrection. Mendes and Koslov (2013) found that White participants demonstrated more positive affiliative nonverbal behavior (smiling and laughing) when paired with Black partners than when paired with other White partners. In six studies utilizing over 4,000 participants, researchers found consistent evidence of a pro-Black bias in admission decisions to an honor society, a bias that appeared to operate outside of conscious awareness even for those with strong egalitarian values (Axt, Ebersole, \& Nosek, 2016). Similar overcorrection effects have been found in other domains. Goh and Hall (2015) revealed a positive correlation between benevolent (but not hostile) sexism and affiliative nonverbal behaviors such as smiling. Goh, Ruben, and Hall (2016) have shown similar overcompensation effects as a function of sexual orientation; participants exhibited warmer nonverbal behaviors toward a man and spent longer talking to him when they thought he was gay than when they thought he was straight.

Paradoxically, these effects are more dramatic for those who exhibit strong implicit bias when they are prompted to interact with members of a disliked group. In one study examining how the IAT predicted same-race and other-race interactions, the researchers assessed implicit attitudes before participants met to discuss a socially charged subject (Shelton, Richeson, Salvatore, \& Trawalter, 2005). The results revealed that, ironically, Black people had more positive impressions of White people who had stronger negative implicit attitudes toward Black people. Apparently, those with more implicit negative attitudes were more likely to compensate for their bias and were perceived to be more engaged in the interaction than those with lower IAT scores. In short, these overcorrection attempts were effective at hiding bias. We do not contend that the overcompensation behaviors are necessarily all good (e.g., benevolent sexism) but rather contend that in contrast to what one would assume, stereotypes interact with social and environmental factors in complex ways, rendering predicting one's behavioral responses to them challenging.

Finally, it is also important to point out that there has been considerable controversy surrounding the IAT. In addition to the controversy surrounding 
the IAT's predictive validity (Oswald et al., 2013, 2015), several researchers argue that the IAT assesses familiarity or simply cultural awareness of stereotypes rather than endorsement of those stereotypes (Arkes \& Tetlock, 2004). In addition, poor test-retest reliability (cf. Fujii, Sawaumi, \& Aikawa, 2015; Lane, Banaji, Nosek, \& Greenwald, 2007) renders such an assessment very difficult to defend when held under legal scrutiny.

\section{Stress and Depletion of Resources}

Another important area of psychological research that has demonstrated meaningful implications for shaping societal and organizational change is the recent research examining how effortful stereotype inhibition depletes individual resources. According to Muraven, Tice, and Baumeister's (1998) limited resource model, individuals possess a singular pool of self-control. This pool is depleted when individuals engage in self-regulatory behavior, and as a consequence, after engaging in acts of self-control (such as maintaining socially desirable behavior while dealing with aversive circumstances like traffic or forcing oneself to constrain one's diet), one is less able to regulate behavior in subsequent interactions (D. D. Wagner \& Heatherton, 2014). The process of stereotype correction requires substantial cognitive and emotional effort (Mendes \& Koslov, 2013). As such, when police officers are exposed to stressful situations, which are exceedingly common in their line of work, they may experience a depletion of resources that leads to an increased likelihood of engaging in behaviors that align with stereotypes. In other words, because most individuals hold stereotypes about others (Arkes, \& Tetlock, 2004; Blanton \& Jaccard, 2006; Rothermund \& Wentura, 2004), when faced with extreme and/or ongoing stress, the ability to mitigate the effect of stereotypes on behavioral outcomes decreases.

Recent empirical research supports the association between resource depletion and stereotype use. Mendes and Koslov (2013) found that positive nonverbal behavioral responses toward stigmatized individuals were attenuated after individuals experienced stress or cognitive load. In a fascinating exploration into how sleep deprivation may be related to police bias, D. T. Wagner, Barnes, and Guarana (2015) found that on the Monday after the daylight saving time shift, police officers conducted significantly more unnecessary searches and arrests not leading to prosecution for Black as opposed to White suspects. Importantly, this research did not show that police officers made more unjustified arrests in general; rather, these arrests were directed at African American suspects, thus it is presumed that impaired sleep was associated with self-regulatory failure, prompting more police harassment of Black individuals. 


\section{Implications and Recommendations for the Workplace}

We contend that rather than implementing screening procedures to identify biased individuals, one recommendation that is more consistent with current research and theory of cognitive processes is to reduce workplace stressors and increase flexibility in the workplace, as these factors prompt individuals to commit errors associated with bias and stereotyping.

Suppressing stereotypes is an extremely taxing endeavor. Individuals are much more likely to rely on stereotypes when tired, when cognitively taxed, and when their resources are depleted (Mendes \& Koslov, 2013). This is particularly problematic for job domains such as law enforcement in which employees work long shifts or compressed workweeks that can be both physically and mentally demanding (Amendola, et al., 2011; van Gelderen, Heuven, van Veldhoven, Zeelenberg, \& Croon, 2007). Research has identified numerous negative physical and mental health outcomes associated with shift work (Griffin, 2016; Kossek, Thompson, \& Lautsch, 2015; Smith, Folkard, Tucker, \& Evans, 2010). Correspondingly, an additional concern for employees working lengthy shifts or compressed workweeks may be a reduced ability to suppress stereotypes, particularly when situations are stressful and fast paced and require immediate decision making.

Ruggs et al. suggest that the way to address these issues is to implement assessment tools that screen for bias into selection systems. However, as mentioned before, the IAT has questionable psychometric properties for selection purposes, in addition to poor ratings of procedural justice (Oswald et al., 2015; Wright \& Meade, 2011). Utilizing unreliable measures that are likely to also have high rates of applicant failure is cause for legal concern. Despite the fact that using psychological criteria as part of a "screening out" selection model is traditional in fields such as law enforcement (Metchik, 1999), there is an overwhelming challenge to recruit and hire quality law enforcement personnel in the United States; this has been termed the "Cop Crunch" (Taylor et al., 2006). Initiating an additional "hoop" for applicants to jump through would likely cause animosity with both applicants and current police officers due to the potential for perceptions of injustice. Finally, it is likely that given the psychometric issues present in these measurements, organizations that attempt to assess potential bias as part of the selection process would likely face legal ramifications in the form of costly lawsuits from disgruntled applicants.

We argue that it is important to first recognize that all individuals possess bias and that increasing awareness of stereotypes can play an important role in reducing their negative impact. Therefore, organizational strategies should strive to reduce workplace factors that attenuate individuals' 
abilities to negotiate complicated situations rather than targeting individuals as potential sources of bias. In line with Muraven et al.'s (1998) strength model, we argue that repeated exposure to workplace stressors may become a cause of resource depletion that could lead employees such as law enforcement officers to rely on stereotypes. Offering training and education about how and why these issues exist, rather than promoting fear of negative decisions, can reduce the cognitive load associated with the stereotype appraisal process.

We contend that an important contribution that industrialorganizational psychologists can make to the reduction of negative outcomes associated with stereotypes is through research and organizational practices that reduce stress and fatigue, particularly for employees working long shifts or compressed workweeks. Research examining interventions designed to reduce workplace stressors has shown remarkable improvements in both employee and employer outcomes, including reduced absenteeism, improved physical and mental health, and increased financial returns (Lamontagne, Keegel, Louie, Ostry, \& Landsbergis, 2007). Another potential solution to reduce stressors experienced by employees working in shiftwork is the practice of flexible shifts or allowing employees some degree of control over when, where, or how they work (Kelly \& Moen, 2007; Kossek, Hammer, Thompson, \& Burke, 2014). This can function to reduce numerous sources of work and nonwork stressors (Kossek \& Thompson, 2016), potentially freeing cognitive resources to focus on job tasks. Consequently, employees in jobs that are both physically and mentally demanding such as law enforcement may particularly benefit from occupational health interventions targeting job stressors that are acutely tied to decision making and cognitive demands in order to reduce the negative behavioral responses associated with bias.

\section{Conclusions}

We agree with the focal article that stereotypes play a role in society and employee decision making, and as members of the Baltimore community, we understand how high the stakes are for improving race relationships. However, there are important insights to be gained from critically examining existing measurement strategies (such as the IAT) and the complexity of the stereotyping literature. Additionally, we identify that some research trends may be controversial and therefore complicated to address in organizational settings through policies and practices. We believe that psychologists can and do play a role in understanding these issues, but until we consider both the recent findings and the very specific context in which organizations exist (legal, ethical, and practical), we cannot draw realistic conclusions about ways that organizations can address these issues. However, 


\section{we believe that these discussions have posed important empirical questions that researchers can begin to address in order to work toward meaningful solutions.}

\section{References}

Amendola, K. L., Weisburd, D., Hamilton, E., Jones, G., Slipka, M., \& Heitmann, A. (2011). The shift length experiment: What we know about 8-, 10-, and 12-hour shifts in policing. Retrieved from http://www.policefoundation.org/wp-content/uploads/2015/06/ShiftLengthExperiment_0.pdf

Arkes, H. R., \& Tetlock, P. E. (2004). Attributions of implicit prejudice, or "would Jesse Jackson 'fail' the Implicit Association Test?" Psychological Inquiry, 15, 257-278.

Axt, J. R., Ebersole, C. E., \& Nosek, B. A. (2016). An unintentional, robust, and replicable pro-Black bias in social judgment. Social Cognition, 34, 1-39.

Blanton, H., \& Jaccard, J. (2006). Arbitrary metrics in psychology. American Psychologist, 61, 27-41. doi:10.1037/0003-066X.61.1.27

Crandall, C. S., \& Eshleman, A. (2003). A justification-suppression model of the expression and experience of prejudice. Psychological Bulletin, 129(3), 414-446. doi:10.1037/0033-2909.129.3.414

Devine, P. G. (1989). Stereotypes and prejudice: Their automatic and controlled components. Journal of Personality and Social Psychology, 56, 5-18.

Fujii, T., Sawaumi, T., \& Aikawa, A. (2015). Test-retest reliability of the Implicit Association Test for measuring shyness: Inclusion of malleability of implicit shyness. Japanese Journal of Psychology, 86, 361-367. doi:10.4992/jipsy.86.14324

Goh, J. X., \& Hall, J. A. (2015). Nonverbal and verbal expressions of men's sexism in mixed-gender interactions, Sex Roles, 72, 252-261. doi:10.1007/s11199-015-0451-7

Goh, J. X., Ruben, M. A., \& Hall, J. A. (2016, January). Positive nonverbal expressions toward gay people. Presented at the Nonverbal Preconference of the 17th annual conference of the Society for Personality and Social Psychology, San Diego, CA.

Greenwald, A. G., McGhee, D. E., \& Schwartz, J. K. (1998). Measuring individual differences in implicit cognition: The implicit association test. Journal of Personality and Social Psychology, 74, 1464-1480. doi:10.1037/0022-3514.74.6.1464

Greenwald, A. G., Poehlman, T. A., Uhlmann, E. L., \& Banaji, M. R. (2009). Understanding and using the Implicit Association Test: III. Meta-analysis of predictive validity. Journal of Personality and Social Psychology, 97, 17-41. doi:10.1037/a0015575

Griffin, R. M. (2016). Coping with excessive sleepiness. Retrieved from http://www.webmd.com/ sleep-disorders/excessive-sleepiness-10/shift-work

Kelly, E. L., \& Moen, P. (2007). Rethinking the clockwork of work: Why schedule control may pay off at work and at home. Advances in Developing Human Resources, 9, 487-506.

Kossek, E. E., Hammer, L. B., Thompson, R. J., \& Burke, L. B. (2014). Leveraging workplace flexibility: Fostering engagement and productivity. In SHRM Foundation (Ed.), SHRM Foundation's Effective Practice Guidelines Series. Alexandra, VA: SHRM Foundation.

Kossek, E. E., \& Thompson, R. J. (2016). Workplace flexibility research: A review of formal and informal approaches. In T. D. Allen \& L. T. Eby (Eds.), Oxford handbook of work and family (pp. 255-270). New York, NY: Oxford.

Kossek, E. E., Thompson, R. J., \& Lautsch, B. A. (2015). Balanced flexibility: Avoiding the traps. California Management Review, 57, 5-25.

Lamontagne, A. D., Keegel, T., Louie, A. M., Ostry, A., \& Landsbergis, P. A. (2007). A systematic review of the job-stress intervention evaluation literature, 1990-2005. International Journal of Occupational and Environmental Health, 13, 268-280.

Lane, K. A., Banaji, M. R., Nosek, B. A., \& Greenwald, A. G. (2007). Understanding and using the Implicit Association Test: IV. What we know (so far) about the method. In B. Wittenbrink, N. Schwarz, B. Wittenbrink, \& N. Schwarz (Eds.), Implicit measures of attitudes (pp. 59-102). New York, NY: Guilford Press. 
Mekawi, Y., \& Bresin, K. (2015). Is the evidence from racial bias shooting task studies a smoking gun? Results from a meta-analysis. Journal of Experimental Social Psychology, 61, 120-130. http: //dx.doi.org/10.1016/j.jesp.2015.08.002

Mendes, W. B., \& Koslov, K. (2013). Brittle smiles: Positive biases toward stigmatized and outgroup targets. Journal of Experimental Psychology: General, 142, 923-933. doi:10.1037/a0029663

Metchik, E. (1999). An analysis of the "screening out" model of police officer selection. Police Quarterly, 2, 79-95. doi:10.1177/109861119900200104

Muraven, M., Tice, D. M., \& Baumeister, R. F. (1998). Self-control as a limited resource: Regulatory depletion patterns. Journal of Personality and Social Psychology, 74, 774-789. doi:10.1037/00223514.74.3.774

Oswald, F. L., Mitchell, G., Blanton, H., Jaccard, J., \& Tetlock, P. E. (2013). Predicting ethnic and racial discrimination: A meta-analysis of IAT criterion studies. Journal of Personality and Social Psychology, 105, 171-192. doi:10.1037/a0032734

Oswald, F. L., Mitchell, G., Blanton, H., Jaccard, J., \& Tetlock, P. E. (2015). Using the IAT to predict ethnic and racial discrimination: Small effect sizes of unknown societal significance. Journal of Personality and Social Psychology, 108, 562-571. doi:10.1037/pspa0000023

Ross, C. T. (2015). A multi-level Bayesian analysis of racial bias in police shootings at the county-level in the United States, 2011-2014. PLoS ONE, 10(11), e0141854. doi:10.1371/journal.pone.0141854

Rothermund, K., \& Wentura, D. (2004). Underlying processes in the Implicit Association Test: Dissociating salience from associations. Journal of Experimental Psychology: General, 133, 139-165. doi:10.1037/0096-3445.133.2.139

Ruggs, E. N., Hebl, M. R., Rabelo, V. C., Weaver, K. B., Kovacs, J., \& Kemp, A. S. (2016). Baltimore is burning: Can I-O psychologists help extinguish the flames? Industrial and Organizational Psychology: Perspectives on Science and Practice, 9(3), 525-547.

Shelton, J. N., Richeson, J. A., Salvatore, J., \& Trawalter, S. (2005). Ironic effects of racial bias during interracial interactions. Psychological Science, 16, 397-402.

Smith, C. S., Folkard, S., Tucker, P., \& Evans, M. S. (2010). Work schedules, health and safety. In L. E. Tetrick \& J. C. Quick (Eds.), Handbook of occupational health psychology (pp. 185-204). Washington, DC: American Psychological Association.

Taylor, B., Kubu, B., Fridell, L., Rees, C., Jordan, T., \& Cheney, J. (2006). Cop crunch: Identifying strategies for dealing with the recruiting and hiring crisis in law enforcement. Washington, DC: U.S. Department of Justice.

van Gelderen, B., Heuven, E., van Veldhoven, M., Zeelenberg, M., \& Croon, M. (2007). Psychological strain and emotional labor among police officers: A diary study. Journal of Vocational Behavior, 71, 446-459. doi:10.1016/j.jvb.2007.09.001

Vanman, E. J., Saltz, J. L., Nathan, L. R., \& Warren, J. A. (2004). Racial discrimination by lowprejudiced Whites facial movements as implicit measures of attitudes related to behavior. Psychological Science, 15, 711-714. doi:10.1111/j.0956-7976.2004.00746.x

Wagner, D. D., \& Heatherton, T. F. (2014). Emotion and self-regulation failure. In J. J. Gross (Eds.), Handbook of emotion regulation (2nd ed., pp. 613-628). New York, NY: Guilford Press.

Wagner, D. T., Barnes, C. M., \& Guarana, C. L. (2015, February). Law and error: The shift to daylight saving time and law enforcement decision making. In A. Gordon \& S. Chen (Chairs), Bringing sleep to social psychology: Considering the effect of sleep on our emotions, relationships and intergroup relations. Symposium presented at the 16th Annual Conference of the Society for Personality and Social Psychology, Long Beach, CA.

Wright, N. A., \& Meade, A. W. (2011, April). Predictive validity and procedural justice of the implicit association test. Paper presented at the 26th Annual Conference of the Society for Industrial and Organizational Psychology, Chicago, IL. 